\title{
Study on the Winter Landscape Construction in the Shadow Area of High-Rise Residential Buildings Taking Shijiazhuang as an Example
}

GUO Yunjia

School of architecture and art, Hebei College of architectural engineering, Qiaodong District, Zhangjiakou, Hebei, China 382672351@qq.com

\begin{abstract}
Under the state-owned and planned economy system of urban land, China's cities have formed a collective housing mode, and the housing supply mode tends to high-rise housing. Due to the transformation of residential form to high-rise and super high-rise buildings, the shadow area of multiple types of buildings is formed. The author hopes to explore the residential landscape design road in the cold area by studying the shadow areas produced by buildings and structures, aiming at the climate conditions in the cold area and combining with the regional characteristics. We hope to improve the residents' unwillingness to socialize, exercise and other activities in the activity space in the shadow area of winter buildings, and create a residential landscape space suitable for all seasons.
\end{abstract}

Keywords: High-rise building, shadow area, winter landscape, Shijiazhuang City

\section{高层住宅建筑阴影区冬季景观营造研究 以石家庄市为例}

\author{
郭昀嘉
}

河北建筑工程学院建筑与艺术学院, 桥东区, 张家口, 河北, 中国 382672351@qq.com

\section{摘要}

在城市土地国有、计划经济体制下, 中国城市形成了集合式住宅模式，住宅供给模式趋于高层住宅。由 于住宅形态转向高层、超高层, 形成多类型建筑阴影区。希望通过研究建筑体、构筑物所产生的阴影 区, 针对寒冷地区的气候条件, 结合地域性, 探索寒冷地区住宅景观设计道路。希望进而改善住户不 愿意在冬季建筑阴影区活动空间进行社交、健身等活动，营造四季皆宜的住宅景观空间。

关键词: 高层住宅, 建筑阴影区, 冬季景观, 石家庄市

\section{1. 我国建筑气候区划与特征}

\section{1. 我国建筑气候区划}

我国地域辽阔, 地形地貌多种多样, 不同的地理位 置与地形地貌导致各地区的气候也复杂多样。（图 1) 根据我国《民用建筑设计通则》, 将我国划分为 7 个主 气候区、20 个子气候区，使得建筑适应当地的气候条 件。我国的建筑气候划分为五个气候区, 分别是严寒地
区、寒冷地区、夏热冬冷地区、夏热冬暖地区、温和地 区。寒冷地区主要是指我国北京、天津、河北、山东、 山西、宁夏、陕西大部、辽宁南部、甘肃中东部、新疆 南部、河南、安徽、江苏北部以及西藏南部等地区。 


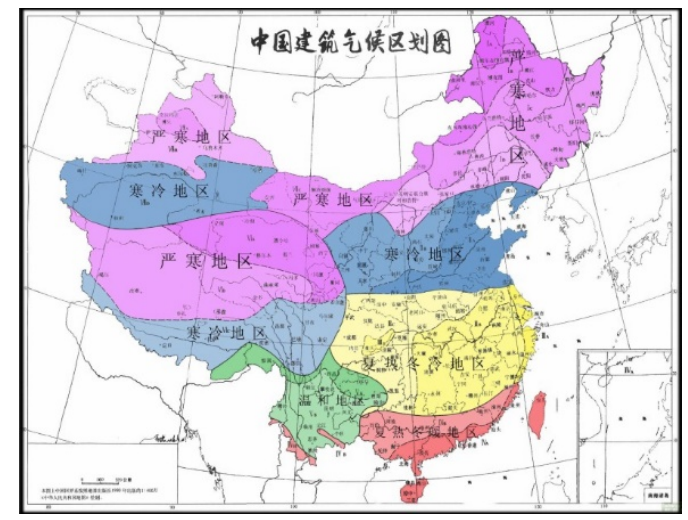

图 1 中国建筑气候划分图

\section{2. 寒冷地区气候特征}

寒冷地区的气候特征为冬季较长而且寒冷干燥, 平 原地区夏季较炎热湿润, 高原地区夏季较凉爽, 降水量 相对集中; 气温年较差较大, 日照较丰富; 春、秋两季 短促, 气温变化剧烈 ; 春季雨雪稀少, 多大风风沙天气, 夏秋两季多冰雹和雷暴。寒冷地区气候主要指标为 1 月 平均气温 $-10^{\circ} \mathrm{C} \sim 0^{\circ} \mathrm{C}, 7$ 月平均气温 $18 \sim 28^{\circ} \mathrm{C}$, 日平 均温度 $\leqslant 5^{\circ} \mathrm{C}$ 达到 $90 \sim 145$ 天。（表 1 ）

\section{表 1 中国分地区建筑基本要求}

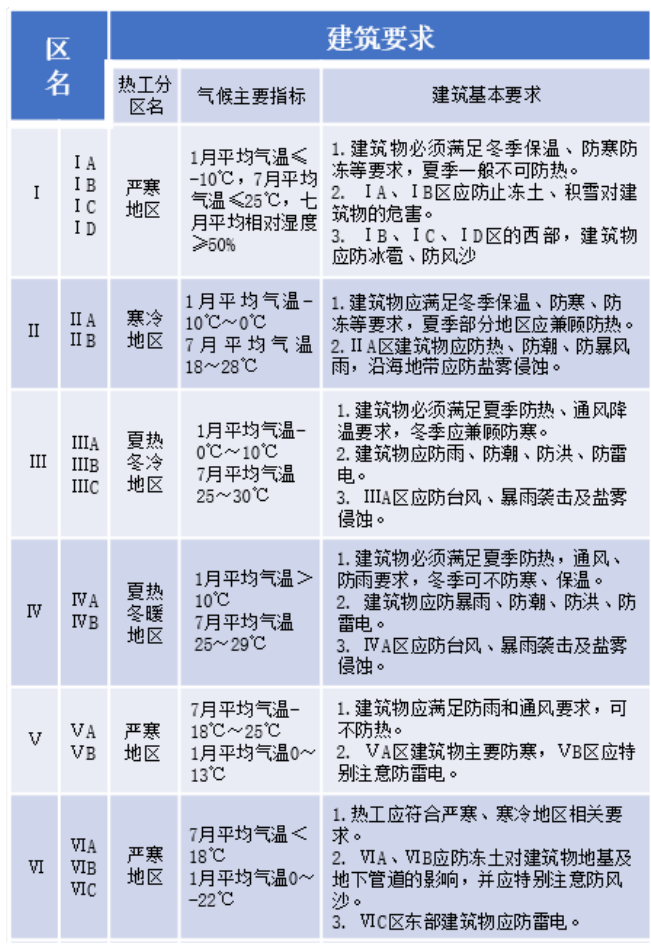

（接上表）

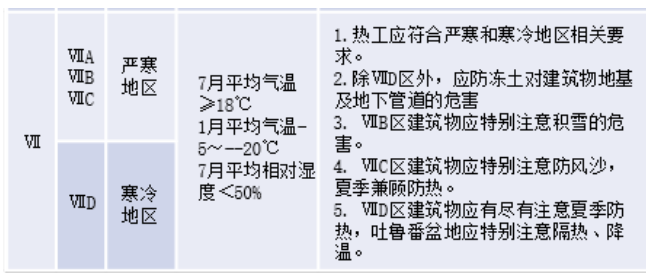

\section{2. 中国住宅}

\section{1. 中国住宅发展历程}

自 1978 年全国实行改革开放政策以来, 住宅建设 实现了快速发展。在 20 世纪 80 年代房地产主要是在 量上解决公民住房问题, 这一时期主要是在被动接受住 宅, 无法选择环境与质量。 20 世纪 90 年代住房数量已 经缓解的前提下，居民也更向往 “质” 的提升。在 1998 年, 经国务院发文实行城镇住房体制改革, 由从前的单 位分配转化为市场经济, 在住宅选择上发生了质的变化。

随着物质生活水平的提高, 住宅建设也由无住宅质 量选择权发展至讲究环境、品质的住宅。将中国住宅发 展主要可分为五个阶段。在第一、第二阶段, 主要是简 单解决居民的基本住房问题; 第三、第四阶段住宅已逐 渐发展为追求住房产品质量与生活品质的层面; 第五阶 段开始着眼于环境, 坚持以人为本, 追求在有限的生存 空间中，与空间、环境、文化、效益等方面有机结合， 建设健康、舒适、安全的住宅, 创造良好的人居环境。

\section{2. 中国住宅供给模式}

在计划经济体制和土地国有化的条件下, 中国形成 集合式住宅模式。在住房制度改革下, 中国城市住宅趋 于高层、高密度型住宅供给模式。在建造过程中, 高层 住宅耗能、耗材且造价高, 同比多层住宅费用成本要多 出 $50 \%$ ～100\%, 在住宅使用年限到期后拆除难度也较高 [1]。

住宅供给模式趋于高层住宅主要原因为土地政策、 资源短缺以及追求高效率资源利用方式。政府追求土地 收入最大化, 住宅用地的市场需求较高, 导致住宅用地 容积率不断提高; 开发商为获取高额利润, 也在不断调 整容积率, 导致发生高层、超高层住宅的建设现象。

\section{3. 建筑阴影区}

太阳光是我们人类以及地球一切生物赖以生存的 基础。太阳光杀死有害细菌的同时, 也为植物提供充足 光线从而进行光合作用。需要太阳光的同时, 阴影对我 们也有所影响。比如上街戴帽、打伞的行人, 利用帽子、 伞具遮挡太阳的辐射, 从而形容阴影区, 在小范围内改 
善环境状态; 夏季人们聚集在树下进行活动也是同理。 建筑阴影区主要是指建筑体周边区域由于日照作用, 该 户外环境处于一定阴影面积。建筑阴影区主要分为三类: a. 永久阴影区、b. 一般阴影区、c. 近阴影区。a. 永久阴 影区主要是指全年任何时段太阳都无法照射到的区域; b. 一般阴影区是指在大多数时段太阳无法照射到的区 域; c. 近阴影区是指在太阳高度角较低的时候, 如早晨、 傍晚, 处于阴影的区域, 但大多数时段有太阳照射。(图 2)

建筑阴影区在除夏季的季节优势不明显, 在冬季只 有起到遮蔽一定紫外线的作用, 同时冬季建筑阴影区缺 少阳光照射, 气温较低, 应运用设计手段, 提高建筑阴 影区对于住户的吸引力。在阴影区中应避免设计绿地和 室外活动场所, 保障住户最大程度上获取阳光。在《城 市居住区规划设计规范》中, 组团绿地设置应满足不少 于 $1 / 3$ 的绿地面积在标准的建筑日照阴影线范围之外 的要求, 并便于设置儿童游戏设施和和适于成人游憩活 动 ${ }^{[2]}$ 。

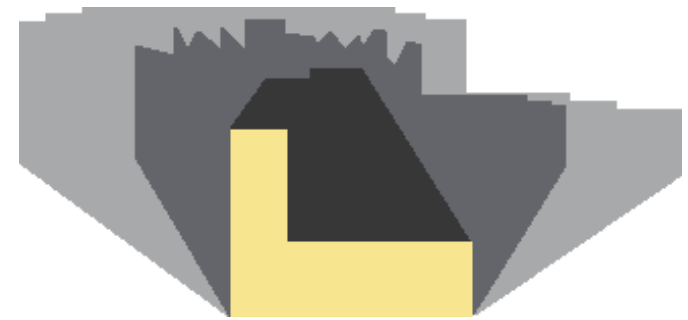

图 2 建筑阴影示意

\section{3. 石家庄住宅冬季景观营造策略}

\section{1. 植物设计}

在住宅植物的选择与配置上, 遵循适地、适树原则, 选用适宜本土生长的树种, 并对本土树种选育栽培, 营 造属于石家庄的地域性植物景观 ${ }^{[3]}$ 。在植物类别配置上, 选取乔木、灌木、地被等多种植物进行组合, 在空间利 用和景观层次方面都能呈现丰富效果; 选取色彩丰富、 形态各异的植物进行搭配, 做到既有变化又与整体环境 相协调。（表 2、表 3、表 4）

\section{表 2 乔木植物类别及形态特征}

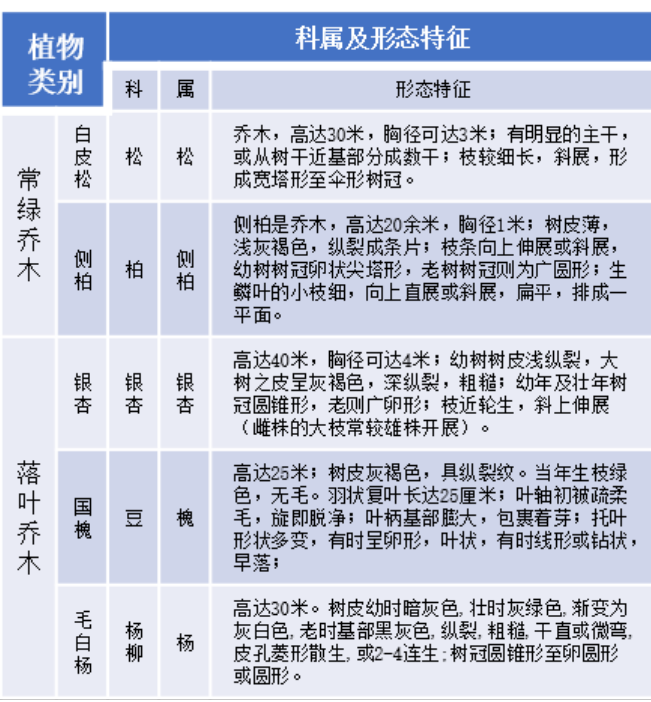

表 3 灌木植物类别及形态特征

\begin{tabular}{|c|c|c|c|c|}
\hline \multirow{2}{*}{\multicolumn{2}{|c|}{$\begin{array}{l}\text { 植物 } \\
\text { 类别 }\end{array}$}} & \multicolumn{3}{|r|}{ 科属及形态特征 } \\
\hline & & 科 & 属 & 形态特征 \\
\hline \multirow{3}{*}{$\begin{array}{l}\text { 常 } \\
\text { 绿 } \\
\text { 灌 }\end{array}$} & $\begin{array}{l}\text { 小 } \\
\text { 叶 } \\
\text { 黄 } \\
\text { 杨 }\end{array}$ & $\begin{array}{l}\text { 黄 } \\
\text { 杨 }\end{array}$ & $\begin{array}{l}\text { 黄 } \\
\text { 杨 }\end{array}$ & $\begin{array}{l}\text { 灌木, 生长低矮, 枝条密集, 节间通常长3-6豪 } \\
\text { 米, 枝圆柱形, 有纵棱, 灰白色; 小枝四棱形, } \\
\text { 全面被短柔毛或外方相对两则面无毛。 }\end{array}$ \\
\hline & $\begin{array}{l}\text { 大 } \\
\text { 叶 } \\
\text { 女 } \\
\text { 贞 }\end{array}$ & $\begin{array}{l}\text { 木 } \\
\text { 犀 }\end{array}$ & 交 & $\begin{array}{l}\text { 枝黄褐色、蝎色或灰色, 圆柱形, 疏生圆形皮孔, } \\
\text { 小枝嫩榄绿色或黄褐色至蝎色, 圆柱形, 节处稍 } \\
\text { 压, 幼时被短柔毛, 后无毛。 }\end{array}$ \\
\hline & $\begin{array}{l}\text { 铺 } \\
\text { 地 } \\
\text { 柏 }\end{array}$ & 柏 & $\begin{array}{l}\text { 圆 } \\
\text { 柏 }\end{array}$ & 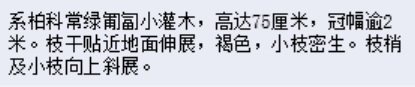 \\
\hline $\begin{array}{l}\text { 落 } \\
\text { 叶 }\end{array}$ & $\begin{array}{l}\text { 金 } \\
\text { 银 } \\
\text { 花 }\end{array}$ & $\begin{array}{l}\text { 忍 } \\
\text { 冬 }\end{array}$ & $\begin{array}{l}\text { 忍 } \\
\text { 冬 }\end{array}$ & $\begin{array}{l}\text { 小枝细长, 中空, 藤为褐色至赤褐色。㚹形叶子对 } \\
\text { 生,枝叶均密生策毛和腺毛。 }\end{array}$ \\
\hline $\begin{array}{l}\text { 灌 } \\
\text { 木 }\end{array}$ & $\begin{array}{l}\text { 珍 } \\
\text { 珠 } \\
\text { 梅 }\end{array}$ & $\begin{array}{l}\text { 葶 } \\
\text { 薇 }\end{array}$ & $\begin{array}{l}\text { 蒂微 } \\
\end{array}$ & $\begin{array}{l}\text { 小枝圆柱形, 稍屈曲, 无毛或微被短柔毛, 初时绿 } \\
\text { 色, 老时暗红褐色或暗黄褐色 }\end{array}$ \\
\hline
\end{tabular}

表 4 草本及藤本植物类别及形态特征

\begin{tabular}{|c|c|c|c|c|}
\hline \multirow{2}{*}{\multicolumn{2}{|c|}{$\begin{array}{l}\text { 植物 } \\
\text { 类别 }\end{array}$}} & \multicolumn{3}{|r|}{ 科属及形态特征 } \\
\hline & & 科 & 属 & 形态特征 \\
\hline \multirow{3}{*}{$\begin{array}{l}\text { 草 } \\
\text { 本 } \\
\text { 植 } \\
\text { 物 }\end{array}$} & $\begin{array}{l}\text { 万 } \\
\text { 寿 } \\
\text { 菊 }\end{array}$ & 菊 & 菊 & $\begin{array}{l}\text { 菜直立, 粗壮, 具纵细条棱, 分枝向上平展。 } \\
\text { 叶羽状分裂, 长5-10厘米, 宽4-8厘米, 裂片长 } \\
\text { 椭圆形或披针形, 边缘具锐锯齿, 上部叶裂片的 } \\
\text { 齿端有长细芒 }\end{array}$ \\
\hline & $\begin{array}{l}\text { 凡 } \\
\text { 寍 } \\
\text { 景 }\end{array}$ & $\begin{array}{l}\text { 景 } \\
\text { 天 }\end{array}$ & 公 & 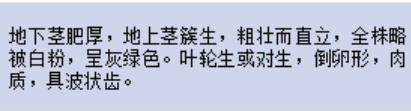 \\
\hline & $\begin{array}{l}\text { 美 } \\
\text { 㚣 } \\
\text { 挧 }\end{array}$ & $\begin{array}{l}\text { 马 } \\
\text { 鞰 } \\
\text { 草 }\end{array}$ & $\begin{array}{l}\text { 马 } \\
\text { 䩲 } \\
\text { 草 }\end{array}$ & 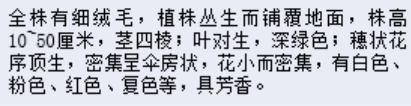 \\
\hline \multirow{2}{*}{$\begin{array}{l}\text { 藤 } \\
\text { 本 } \\
\text { 植 } \\
\text { 物 }\end{array}$} & $\begin{array}{l}\text { 冬 } \\
\text { 紫 } \\
\text { 罗 }\end{array}$ & 菊 & $\begin{array}{l}\text { 蜂 } \\
\text { 斗 } \\
\text { 菜 }\end{array}$ & $\begin{array}{l}\text { 直立, 基部稍木质化。叶面宽大, 长椭圆形或倒 } \\
\text { 损铏, 先端圆钝。 }\end{array}$ \\
\hline & $\begin{array}{l}\text { 地 } \\
\text { 锦 }\end{array}$ & $\begin{array}{l}\text { 莗 } \\
\text { 萄 }\end{array}$ & $\begin{array}{l}\text { 地 } \\
\text { 锦 }\end{array}$ & $\begin{array}{l}\text { 小枝圆柱形, 几无毛或微被疏柔毛。卷须5-9分枝, } \\
\text { 相隔2节间断与叶对生。 }\end{array}$ \\
\hline
\end{tabular}




\section{2. 铺装设计}

石家庄冬季多有降雪, 造成路面湿滑, 选取摩擦力 大的铺装材料, 降低滑倒摔伤的危险性。选取浅且暖的 颜色，搭配以装饰性的花纹图案，给住户以温暖的心理 暗示, 同时注意与周遭环境的融合 ${ }^{[4]}$ 。根据场地主要使 用人群特性、活动特点, 进行铺装配置。如儿童活动场 地, 应选取活泼、明艳的颜色, 同时考虑童车通达性以 及儿童好动的性格。

\section{3. 构筑物设计}

休息设施。老年人是住区构筑物使用频率较高的人 群, 在座椅布局上, 应缩小座椅间隔, 同时考虑座椅季 节使用性，减少在建筑阴影区设置座椅，考虑见阳处。 选取的座椅材料应具有较高强度、良好质感、以及导热 性差等特点, 铁艺、石材座椅夏季吸热快, 冬季冰冷, 降低住户使用频率和使用时间，应选取塑料、木制座椅 进行设置。

健身设施。体育器材类设施在实现住户健身的同时 成为住区景观一部分, 以明艳的色彩与良好的形态设计, 更能在冬季吸引人注意, 激起住户对运动的渴望 ${ }^{[5]}$ 。

\section{4. 水体设计}

水体在夏季可以增加住区景致及趣味, 冬季容易存 在安全隐患, 对水资源也是极大的消耗, 维护成本也较 高。考虑石家庄地区冬季气候特征, 运用旱溪景观, 模 仿自然界干涸的河床, 同时搭配以植物, 形成溪水意境。 同时也可以运用到缺水或气候条件恶劣地区 ${ }^{[6]}$ 。

\section{项目基金}

本文为河北建筑工程学院硕士研究生创 新基金项目 XY202022《寒冷地区住宅建筑阴 影区冬季景观营造研究——以石家庄市为例》 的阶段性成果之一。

\section{References}

[1] Li Xj. (2020) High-rise housing is the heaviest social burden in the future of Chinese Society. Architecture times: shanghai.

[2] Zhao Qn, Li J. (2011) On the design of space environment in the shadow area of Architecture. Annual meeting of urban planning in China.nanjing.8860-8866.
[3] Chen Mn. (2004)Study on winter landscape construction of Shijiazhuang City Park. Central South University of forestry science and technology: changsha.

[4] Lu L. (2012) Study on the design of residential landscape pavement. Nanjing agricultural university : nanjing.

[5] Gong Cy. (2014) Study on the construction of winter landscape environment in the residential area of cold area. Jilin University of Architecture: changchun.

[6] Yang Mh. (2017) Study on landscape design of residential area in low temperature area-Take tianyi lanwan residential area in Harbin city as an example. Chongqing university: chongqing. 